Original Article

\title{
TASTE MASKING BY HOT MELT EXTRUSION WITHOUT LOSS OF BIOAVAILABILITY FOR PEDIATRICS
}

\author{
DHANANJAY M.1* ${ }^{*}$ PRAVEEN C. ${ }^{2}$, SMITA M. ${ }^{3}$
}

1,2Department of Pharmaceutics, Modern College of Pharmacy, Yamunanagar, Nigdi, Pin Code 411044, Savitribai Phule University of Pune, Maharashtra, Indias, ${ }^{3}$ Department of Pharmaceutics, Modern College of Pharmacy (For Ladies), Moshi, Pin Code 412105, Savitribai Phule University of Pune, Maharashtra, India

Email: moredm@gmail.com

Received: 08 Apr 2019 Revised and Accepted: 17 May 2019

\section{ABSTRACT}

Objective: The aim of present work was to develop a platform technology for the pediatric dosage form to mask the bitter taste of Furosemide (FUR) and prepare a flexible solid oral dosage form.

Methods: Excipient compatibility study was carried out by using Fourier-transform infrared spectroscopy (FTIR). Taste masking was done by hot melt extrusion (HME) technology. Eudragit EPO and Soluplus were used as a taste masking and solubilizing polymers respectively. The prepared solid dispersion and tablets were evaluated for their physicochemical parameters such as hardness, friability, disintegration, in vitro drug release.

Results: Experimental data revealed that physical integrity, brittleness of granules, conversion of a drug in amorphous form was improved by combining Eudragit EPO with Soluplus. Plasticizer helped to complete HME at $80^{\circ} \mathrm{C}$. Less than $10 \%$ drug release in pH 6.8 medium revealed that release would be extremely limited in the saliva and thus avoiding bitterness. Animal study data revealed that bioavailability has been increased by 30\%. Differential scanning calorimetry (DSC) and x-ray diffraction (XRD) tests confirmed the existence of molecularly dispersed drug. Fouriertransform infrared spectroscopy (FTIR) confirmed the unchanged functional groups of FUR after HME processing.

Conclusion: Proposed platform technology masked the bitter taste and enhanced the bioavailability of FUR in D: P ratio of 1:2.

Keywords: Hot Melt Extrusion, Solubility, Dissolution, Pediatric dosage, Taste Masking

(C) 2019 The Authors. Published by Innovare Academic Sciences Pvt Ltd. This is an open access article under the CC BY license (http://creativecommons.org/licenses/by/4.0/) DOI: http://dx.doi.org/10.22159/ijpps.2019v11i7.33493

\section{INTRODUCTION}

Different options are regularly used to make unavailable drugs available for pediatric patients and to adjust doses according to an individual patient's requirement. Such choices are a modification of administration routes (eg. oral use of parenteral formulations), manipulation of adult dosage forms (eg, diluting liquid formulations), segmenting tablets and suppositories, cutting patches, and dispersing capsule content or crushed tablets in water, liquid, or food, or spontaneous dispensing (compounding medicines from ingredients within pharmacies) [1].

Disadvantages of oral pediatric dosage forms are the requirement of dose-measuring devices, chances of incorrect dosing, shaking requirement for dose accuracy in the liquid dosage form and the ability to swallow intact dosage form, a risk of chewing and choking, limited dose flexibility, taste masking requirements, less stability of liquid dosage form.

The solid oral dosage form is one of the most preferred dosage forms in adults. The main challenges in the development of solid oral dosage form for pediatrics are palatability and acceptance of dosage form due to their bitter taste, obnoxious odor, unattractive finished product appearance, handling and dose measurement/accuracy issues, and many others $[1,2]$.

There may be no single oral dosage form which is ideal for pediatric patients of all ages [3].

The present research work aimed to mask the bitter taste of FUR and prepare chewable dispersible tablet which can overcome all above-mentioned challenges and disadvantages, and accomplishes the desired features.

FUR was selected as a model drug which is bitter in taste and belongs to the biopharmaceutics classification system (BCS) class IV [4] and has a pH-dependent solubility [5]. The pediatric dose and minimum dose of FUR is $2 \mathrm{mg} / \mathrm{kg}$ and $20 \mathrm{mg}$ respectively [6]. The presence of an amine as a functional group make drugs like FUR bitter in taste however if the functional groups are blocked the bitterness of the drug reduces drastically [7]. FUR is a loop diuretic act primarily by inhibiting chloride and sodium reabsorption over the entire length of the thick ascending limb of the loop of henle, it is widely used for the symptomatic treatment of heart failure and fluid retention in chronic kidney disease [8].

Various types of taste masking methods are available which involve multiple steps with scale-up challenges. So, hot melt extrusion (HME) method was selected as taste masking technique due to its unique advantages like easy to scale up and reproducibility [9].

HME technology is an innovative technology which can be used for taste masking of bitter drugs with a unique advantage over other available technologies [10,11]. Different polymer(s) can be used alone or in combination for taste masking of bitter drugs to get desired results, examples are copovidone (kollidon VA 64), polymethacrylic acid copolymer (eudragit EPO), polyvinyl caprolactam (soluplus), ethyl cellulose, etc. Additionally, these polymers can be used for solubility enhancement of poorly soluble drugs [12-14].

In the present work, eudragit EPO is selected as taste masking polymer as it's the only polymer having reverse enteric properties (pH-dependent solubility). It is soluble below $\mathrm{pH} 5$ and swellable and permeable above $\mathrm{pH} 5$ [15]. It is a cationic copolymer based on dimethylamino-ethyl methacrylate, butyl methacrylate, and methyl methacrylate which is insoluble above pH 5 [16]. Soluplus is selected to enhance the solubility of the drug and used in combination with eudragit EPO. Soluplus is polyvinyl caprolactam-polyvinyl acetatepolyethylene glycol graft copolymer which is freely water-soluble [16]. These polymers were selected to have a rapid gastric release of FUR in the stomach. By using these two polymers we intend to examine the correlation between in vitro drug release and taste masking efficiency. Possible taste masking mechanism would be intermolecular ionic 
interactions between an amine and carboxylic groups of active pharmaceutical ingredients (API) and eudragit EPO respectively [17].

In the present study plasticizers like polyethylene glycol (PEG) and polysorbate were used as plasticizer and para glycoprotein (Pgp) as inhibitors/surfactant $[18,19]$ respectively and their impact on solubility and permeability was evaluated.

\section{MATERIALS AND METHODS}

\section{Materials}

Furosemide of Ralington Pharma (India), Eudragit EPO of Evonik Pharma, Soluplus of BASF, Crospovidone of Ashland, Mannitol of Roquette, Sodium Stearyl Fumarate of JRS Pharma, Colloidal silicon dioxide of Evonik, Iron oxide red of Neelikon food dyes and chemicals, Raspberry flavor by Kerry, were used in present research work.

\section{Methods}

\section{An analytical method for calibration curve of FUR}

Maximum wavelength of FUR was found to be $274 \mathrm{~nm}$ using UV visible spectroscopy (Make: Shimadzu, Model: 1800). Stock solution $(100 \mu \mathrm{g} / \mathrm{ml})$ was prepared with $0.01 \mathrm{~N}$ HCL with $2 \%$ sodium lauryl sulfate (SLS). Aliquots of stock solution ranging from 1.0 to $7.0 \mathrm{ml}$ were transferred into $10 \mathrm{ml}$ volumetric flask and were diluted up to the mark with $0.01 \mathrm{~N}$ HCL with $2 \%$ SLS to get concentrations of 10 , $20,30,40,50,60,70 \mu \mathrm{g} / \mathrm{ml}$. The Absorbance of each solution was measured at $274 \mathrm{~nm}$ against $0.01 \mathrm{~N}$ HCL with $2 \%$ SLS. A plot of concentration of drug versus absorbance was plotted. The linear regression analysis was applied. The standard regression equation for FRU obtained was $\mathbf{Y}=0.2019 \mathrm{x}-0.1726$ with a coefficient of regression $\left(R^{2}\right)$ of 0.9993 . The Same procedure was followed to generate the calibration curve in $\mathrm{pH} 6.8$ phosphate buffer where the standard regression equation for FRU obtained was $\mathrm{Y}=0.1910 \mathrm{X}-0.1686$ with a coefficient of regression $\left(\mathrm{R}^{2}\right)$ of 0.9982 .

\section{Determination of the drug: polymer ratio (solubilization capacity)}

Different solvents like methanol, ethanol and distilled water were used for determination of the solubility of the drug and polymers. Drug and polymers were observed to be soluble in methanol, hence selected for further study. For optimization, different ratio of drug and polymer like 1:1 to 1:3 were used. The proportionate amount of drug and polymer was dissolved in methanol and these liquid samples were poured into the Petri dishes. The pure drug was also dissolved in methanol and used as a control sample. The solvent in the samples was evaporated by the evaporation method and appearance of samples was recorded for clearness and transparency at the initial stage and after $24 \mathrm{~h}$ storage at room temperature [20].

\section{Preparation and evaluation of SD granules prepared by HME} technology

FUR, eudragit EPO, soluplus, polysorbate and silicon dioxide (table 1) were sifted through \#30 sieve and mixed in a polybag for $10 \mathrm{~min}$. Liquid PEG mixed in dry powder to get a uniform blend. Obtained blend was screened through \# 18 sieve and used for HME process.

Table 1: Composition of chewable dispersible tablets

\begin{tabular}{|c|c|c|c|c|c|c|c|c|c|}
\hline & \multicolumn{3}{|c|}{ D: P (1:1) } & \multicolumn{3}{|c|}{ D: P (1:2) } & \multicolumn{3}{|c|}{ D: P (1:3) } \\
\hline Formulation & F2 & F2 & F3 & F4 & F5 & F6 & F7 & F8 & F9 \\
\hline Ingredients & \multicolumn{9}{|c|}{ Quantity } \\
\hline & \multicolumn{9}{|c|}{ HME granules part } \\
\hline FUR (mg) & 20 & 20 & 20 & 20 & 20 & 20 & 20 & 20 & 20 \\
\hline Eudragit EPO (mg) & 20 & 20 & 20 & 40 & 40 & 40 & 60 & 60 & 60 \\
\hline Soluplus* & 25 & 25 & 25 & 25 & 25 & 25 & 25 & 25 & 25 \\
\hline Polyethylene glycol* & 5 & 10 & 15 & 5 & 10 & 15 & 5 & 10 & 15 \\
\hline Polysorbate* & 5 & 10 & 15 & 5 & 10 & 15 & 5 & 10 & 15 \\
\hline Silicon dioxide* & 1 & 1 & 1 & 1 & 1 & 1 & 1 & 1 & 1 \\
\hline \multirow[t]{3}{*}{ Total (mg) } & 47.2 & 49.2 & 51.2 & 74.4 & 78.4 & 82.4 & 101.6 & 107.6 & 113.6 \\
\hline & \multicolumn{9}{|c|}{ Extragranular excipient part } \\
\hline & qs & qs & qs & qs & qs & qs & qs & qs & qs \\
\hline Total (mg) & 101.7 & 106.0 & 110.3 & 160.3 & 169.0 & 177.6 & 219.0 & 232.0 & 244.8 \\
\hline
\end{tabular}

HME: Hot melt extrusion, D: FUR, P: Eudragit EPO, F: Formulation, *\%w/w of eudragit quantity

HME was carried out using Pharma 11 model of Thermo scientific. It was twin-screw extruder with $11 \mathrm{~mm}$ screw diameter and $440 \mathrm{~mm}$ in length. Screw diameter to length ratio was 1:40. There were 8 heating zones out of which 2 were mixing zones and others were conveying zones. Screws were co-rotating at the speed of 80-100 rpm; the processing temperature of different zones was set in increasing order and $80{ }^{\circ} \mathrm{C}$ was set in mixing zones. The Powder blend was slowly added to a hopper. Screw speed and feed rate were optimized to get torque in the range of 40-70\% and residence time less than $1 \mathrm{~min}$ for smooth processing. The extrudates were collected as strands with a diameter of approximately 2 $\mathrm{mm}$ and further milled and sifted through \#40 sieve to get final taste masked granules. HME granules were evaluated for saturation solubility, FTIR, DSC and XRD tests as given below.

\section{Saturation solubility}

An excess amount of pure drug and HME granules were added to $0.01 \mathrm{~N}$ hydrochloric acid (HCL) with 2\% SLS and was kept for shaking up to $48 \mathrm{~h}$ (Orbital shaking incubator, Make: Remi) at $37 \pm 0.5{ }^{\circ} \mathrm{C}$ with intermittent vigorous shaking. Filtration of the suspension was done using a $0.45 \mu$ membrane filter, followed by measuring the absorbance of filtrate using UV visible spectrophotometer to determine the concentration of drug [21].

\section{Fourier transform infrared spectroscopy (FTIR)}

FTIR was carried out to find out and ensure the presence and no change in functional groups of the drug before and after HME processing using FTIR spectrophotometer (Make: Jasco, Model: V538). Samples were triturated with potassium bromide (KBr), which were further used to form a pellet. Scanning was done in the range of 400-4000 wavelength $\left(\mathrm{cm}^{-1}\right)$.

\section{Differential scanning colorimetry (DSC)}

Thermal behavior, physical state and melt endotherm of the drug were examined by DSC. The thermographs of each powder sample were obtained by using a Mettler Toledo-DSC 1. DSC was also used to confirm the conversion of a crystalline form of drug into amorphous form after HME processing. The sample was accurately weighed $(5-10 \mathrm{mg})$ and was placed into the suitable aluminum pan and heated from 50 to $250^{\circ} \mathrm{C}$ at the scanning rate of $10^{\circ} \mathrm{C} / \mathrm{min}$ in a nitrogen atmosphere (purging of $50 \mathrm{ml} / \mathrm{min}$ ). FTIR and DSC were also used as identification tests.

\section{Powder X-Ray diffraction (PXRD)}

XRD was carried out at room temperature using a $\mathrm{D} / \mathrm{max}$ 2500VL/PC powder X-ray diffractometer (Rigaku mini flex, Japan) operating at $40 \mathrm{kV}$ and $40 \mathrm{~mA}$ to determine the presence of crystals in HME granules. Samples were scanned over a $2 \theta$ range of $3-40{ }^{\circ}$ with a step size of $0.02^{\circ}$ and a step time of $0.3 \mathrm{~s}$.

\section{Tablet preparation and evaluation}

Extra granular excipients screened through \# 40 sieve and mixed HME granules in a polybag for $10 \mathrm{~min}$. Tablets equivalent to a $20 \mathrm{mg}$ 
dose of FUR were prepared by $7.0 \mathrm{~mm}$ round shape punch using 8 stations single rotary compression machine (Make: CIP machineries, Model: CIP D8 Lab Press). The prepared tablets were evaluated for friability (Make: Electrolab, Model: EF-2) according to United States pharmacopeia (USP) general chapter 1216 [22]. The diametral compression test defined by Fell and Newton [23] was used to determine the tensile strength T, using the formula:

$$
\mathrm{T}=\frac{2 \mathrm{P}}{\pi \mathrm{Dt}}
$$

Where $\mathrm{P}(\mathrm{kP})$ is the applied stress, $\mathrm{D}(\mathrm{cm})$ is the diameter of the tablet, and $\mathrm{t}(\mathrm{cm})$ is the tablet thickness. Tablets were also evaluated for disintegration time and dissolution.

\section{Disintegration time (DT)}

DT of tablets was determined as per the process mentioned in USP general chapter 701[24].

\section{Dissolution (simulation of drug release in the oral cavity)}

Dissolution testing was conducted in $900 \mathrm{ml}$ of two different media (i.e. $0.01 \mathrm{~N} \mathrm{HCL}$ with $2 \% \mathrm{w} / \mathrm{w}$ SLS and $\mathrm{pH} 6.8$ phosphate buffer) for 45 min (at an interval of 5, 15, 30, $45 \mathrm{~min}$ ) using USP Type II apparatus (Make: Electrolab, Model: TDT-06L) at $50 \mathrm{rpm}$ and temperature $37^{\circ} \mathrm{C} \pm 0.5^{\circ} \mathrm{C}$. At every time point, $10 \mathrm{ml}$ aliquots were withdrawn, filtered through membrane filter paper (Whatman 0.45 $\mu$ ) and checked for content by measuring the absorbance at $274 \mathrm{~nm}$ using UV visible spectrophotometer.

An equal volume of fresh medium pre-warmed at the same temperature was replaced in the dissolution medium after each sampling to maintain constant volume throughout the test. Each test was performed on three tablets, and release curves were plotted using calculated mean values of cumulative drug release. Dissolution in $0.01 \mathrm{~N}$ HCL with $2 \% \mathrm{w} / \mathrm{w}$ SLS and $\mathrm{pH} 6.8$ buffer was required to predict release in the stomach and oral cavity respectively (in vitro taste masking efficiency) [25].

\section{Stability study}

Tablets (F6) were packed in heavyweight high-density polyethylene (HDPE) bottle with $2 \mathrm{~g}$ of silica gel canister with cotton filler and closed with a child-resistant closure (CRC). These samples were stored in the stability chamber (Make: Thermo lab scientific equipment) at accelerated $\left(40{ }^{\circ} \mathrm{C} \pm 2{ }^{\circ} \mathrm{C}\right.$ and $\left.75 \% \pm 5 \% \mathrm{RH}\right)$, intermediate $\left(30^{\circ} \mathrm{C} \pm 2{ }^{\circ} \mathrm{C}\right.$ and $\left.65 \% \pm 5 \% \mathrm{RH}\right)$ and long term $\left(25^{\circ} \mathrm{C} \pm 2\right.$ ${ }^{\circ} \mathrm{C}$ and $60 \% \pm 5 \% \mathrm{RH}$ ) stability conditions up to 6 mo. Stability samples were analyzed after 3 and 6 mo for physical appearance, DT, dissolution XRD and FTIR [26].

\section{Animal study}

Due permission was obtained from the animal ethical committee and study was completed as per protocol No. SGRS/IAEC/ 12/201819.

Healthy male and female rats of Wistar strain, weight $200 \pm 15$ g were obtained from the in house animal store of SGRS college of Pharmacy, Saswad, Pune and used to carry out the procedure. The rats were kept in environmentally controlled rooms at temperatures of $23{ }^{\circ} \pm 2{ }^{\circ} \mathrm{C}$. The relative humidity was at least $40 \%$ in rooms and a 12 -hr light/dark cycle was maintained. The animals were kept in suspended steel cages with wire-mesh fronts and floors and were given water and stock diet.

The rats have fasted overnight with free access to water before administration of drugs. Suspension of FUR was prepared in $1 \%$ Carboxymethyl Cellulose (CMC) solution. After a single oral administration of $20 \mathrm{mg} / \mathrm{kg}$ of Frusemide blood samples were collected from the retro-orbital plexus sinus at different time-points (15 $\mathrm{min}, 30 \mathrm{~min}, 1 \mathrm{~h}, 2 \mathrm{~h}$ and $5 \mathrm{~h}$ ). Blood samples were transferred in pre-treated tubes with anticoagulant and centrifuged at 3500 rotations/min for $10 \mathrm{~min}$ in a cooling centrifuge at a constant temperature of $4{ }^{\circ} \mathrm{C}$. The separated plasma was transferred in Eppendorf microtubes and kept on $-20^{\circ} \mathrm{C}$ until analyzed. All the samples of the same animal were analyzed on the same day to avoid variation among analysis. Sample plasma concentration was determined by High-Pressure Liquid Chromatography (HPLC). An HPLC (Shimadzu, SPD 20A, UV visible detector) and RP-C18 column ( $5 \mu \mathrm{m}$ particle size) was used. The RP-HPLC system was equipped with LC CHROM software for data processing. The method was developed using a HIQ SIL, C18 $(250 \times 4.6 \mathrm{~mm}, \mathrm{Fm})$ column. The mobile phase was used for the preparation of drug samples throughout the analysis. For preparing the mobile phase 50 mmol phosphate buffer ( $\mathrm{pH}$ adjusted to 3.0 ) and acetonitrile were mixed together in the ratio of $50: 50 \% \mathrm{v} / \mathrm{v}$. It was filtered before use through $0.45 \mu$ membrane filter and then degassed ultrasonically for $15 \mathrm{~min}$. Flow rate employed was $1.0 \mathrm{ml} / \mathrm{min}$. Detection was carried out at $283 \mathrm{~nm}$ at $25^{\circ} \mathrm{C}$.

\section{RESULTS AND DISCUSSION}

\section{Determination of the drug: polymer ratio}

Drug: Polymer ratio optimization study showed opaqueness in pure FUR sample after storage for a period of $24 \mathrm{~h}$ at room temperature indicating the occurrence of recrystallization during storage. This was possibly due to the free movement of FUR molecules during storage leading to nucleation and recrystallization. Whereas samples containing drug: polymer in the ratio of $1: 1$ to $1: 3$ observed clear after storage. It designates the importance of selected polymers to hold the solubilized form of FUR during storage. FUR was found stable and solubilized in all polymer ratios of $1: 1$ to $1: 3$.

\section{Evaluation of SD granules}

The recommended dissolution media for FUR tablet is $\mathrm{pH} 5.8$ phosphate buffer [27]. As eudragit EPO is soluble below pH 5, saturation solubility was determined in $0.01 \mathrm{~N} \mathrm{HCL}$ with $2 \%$ SLS instead of water. The solubility of all SD was observed about $0.15 \pm 1.2 \mathrm{mg} / \mathrm{ml}$ compared to $18 \pm 1.5 \mu \mathrm{g} / \mathrm{ml}$ of pure FUR.

Saturation solubility of all solid dispersions was increased compared to pure FUR. All three drug: polymer ratios revealed a similar improvement in saturation solubility, so 1:2 ratio was finalized for further development. 1:1 and 1:3 ratios were not finalized due to the processing risk and pill burden due to the increased weight of tablets respectively. The probable reason for solubility enhancement was the formation of a solid solution and conversion of the drug into an amorphous form.

When the HME process was tried at $70{ }^{\circ} \mathrm{C}$ the high $\%$ torque (More than $70 \%$ ) and friction noise of the screw was observed. So, HME processing was completed at increased temperature by $10^{\circ} \mathrm{C}$ i.e. 80 ${ }^{\circ} \mathrm{C}$ which gives optimum $\%$ torque (less than $60 \%$ ) and no noise of screws. As the concentration of plasticizer increases the \% torque and screw friction noise decreases.

DSC and XRD data of all SD samples shows the absence of a sharp peak mostly observed due to crystalline form. FTIR values of samples were similar to that of pure drug. Comparative DSC, XRD thermograms and FTIR values of FUR and SD are presented in fig. 1, 2 and table 2 respectively.

Soluplus is polymeric solubilizer with an amphiphilic chemical structure, which is particularly developed for solid solutions. Due to its bifunctional character, it is able to act as a matrix polymer for solid solutions and is capable of solubilizing poorly soluble drugs in aqueous media [28].

Additionally, specific interactions of the polymer with itself, the drug, and the aqueous medium can result in a range of solubilizing structures, including micelles, colloids, and ionic complexes. Examples of such solubilizers include soluplus (BASF), affinisol (Dow), eudragit E, and eudragit L 100-55 (Evonik) [29]. 


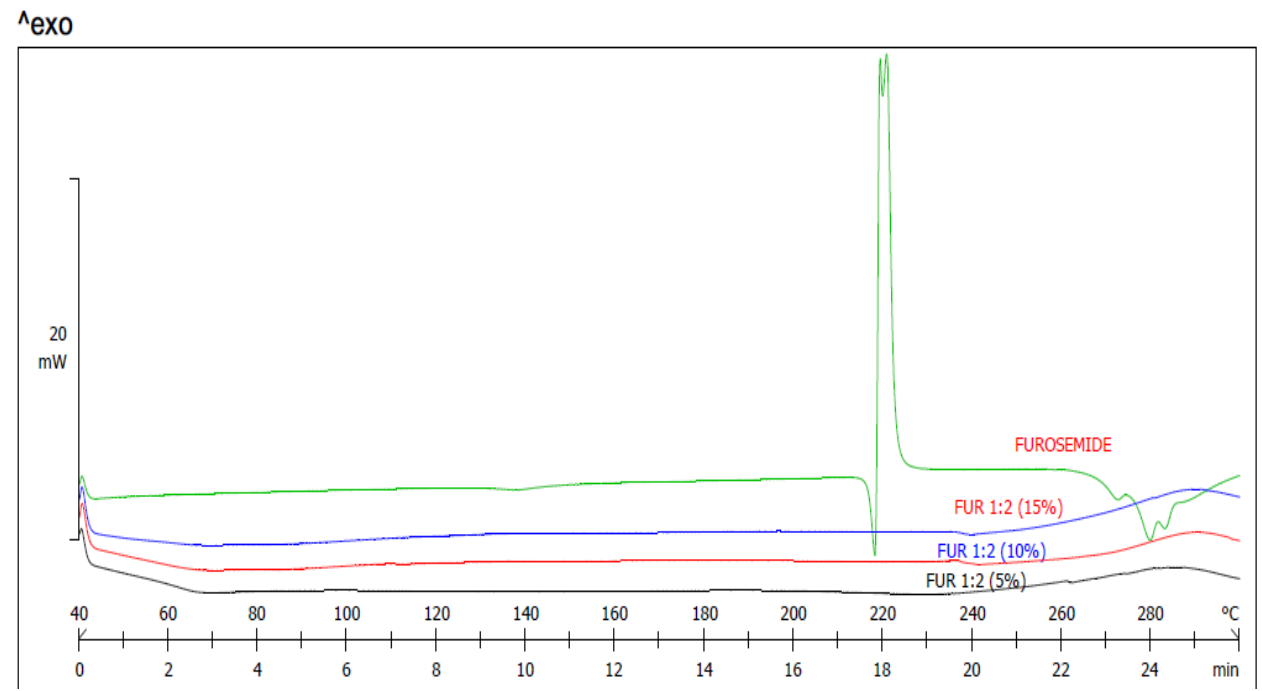

Fig. 1: DSC thermograms of pure FUR (drug), HME formulations of drug: polymer ratio 1:2 (5\%, 10\%, 15\% PEG)

DSC study enables the quantitative detection of all processes in which energy is required or produced (i.e., endothermic or exothermic phase transformations). DSC thermogram of FUR shows it's melting at $218^{\circ} \mathrm{C}$ as presented in fig. 1 .

Thermograms showed a clear, sharp and symmetric peak of FUR. HME granules of D: P 1:2 ratio with 5, 10 and $15 \%$ of plasticizers showed single Tg with no other peak in thermograms endorsed the complete conversion of crystalline form to amorphous due to its solubilization in a polymeric matrix.
Glass transition temperature (Tg) of eudragit EPO and soluplus were $48{ }^{\circ} \mathrm{C}$ and $71{ }^{\circ} \mathrm{C}$ respectively $[13,15]$. Due to lower Tg of both polymers, they melted easily at $80{ }^{\circ} \mathrm{C}$ which was the minimum possible processing temperature. FUR was solubilized and distributed uniformly in the molten mass with the help of rotating screws and mixing zone assembly of hot melt extruder. The possibility of FUR degradation during HME processing was minimized as it was exposed to a temperature for a short duration of time.

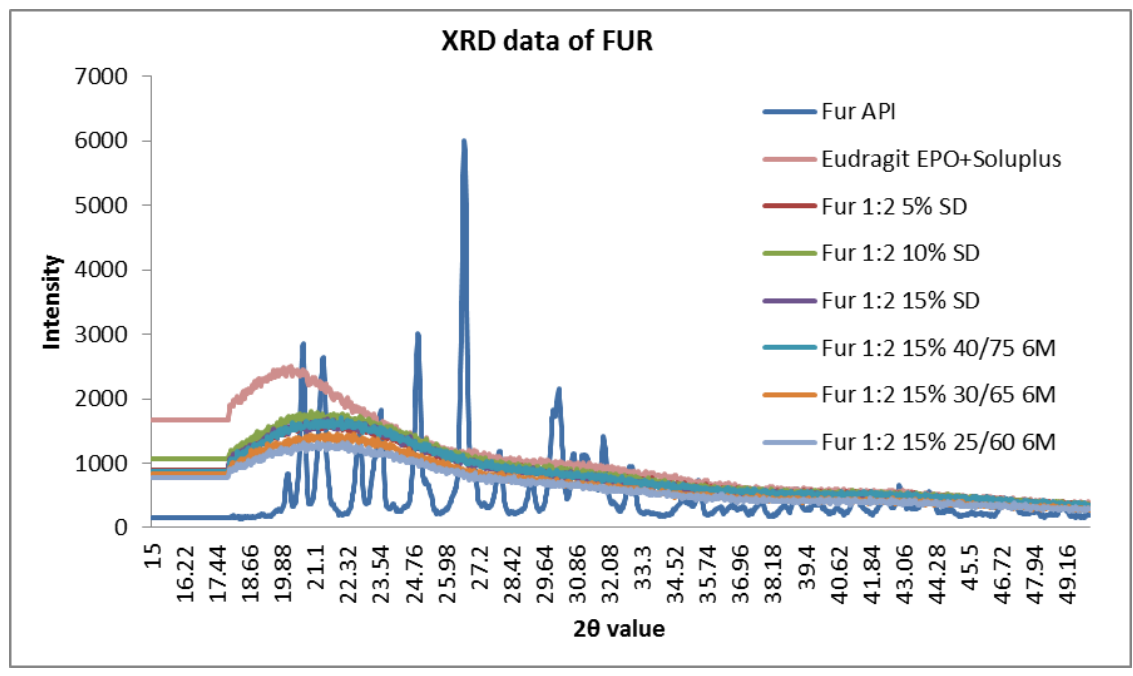

Fig. 2: XRD of pure FUR (drug), a mixture of polymers, HME formulations of drug:

Polymer ratio $1: 2(5 \%, 10 \%, 15 \%$ PEG and polysorbate) and stability samples of $F 6$ at 6-mo time point

XRD is a fundamental technique used to detect a crystalline form of substance and data shows that FUR was in crystalline form. The absence of sharp peaks in the polymer sample confirmed their amorphous nature. In fig. 2, XRD data shows sharp peaks of FUR and absence of peaks in SD samples confirmed the amorphous form of FUR after HME.

FTIR has been used to assess the interaction between the carrier and guest molecules in the solid state. During the SD preparations, there may be a peak band shift in the absorption spectrum of the guest. However, some of the changes are very subtle, requiring careful interpretation of the spectrum [30]. FTIR spectra of FUR showed similar peaks like its standard values as mentioned in table 2 . This study was conducted to explore any interaction or incompatibility between drug and excipients. Data shown in table 2 indicates that there was no change in key functional groups of FUR even after HME processing at $80^{\circ} \mathrm{C}$ compared to pure drug. FTIR spectrum of FUR and formulations showed similar characteristic peaks as per the standard values so confirmed the absence of chemical interaction between drug and excipients during and after HME processing. The important aspect of HME process was to set the minimum possible temperature to avoid any chemical change in functional groups and chemical degradation. FTIR data assured that $80^{\circ} \mathrm{C}$ was the desired temperature to run the HME process smoothly without any chemical change in FUR. Moreover, all the spectra showed no peaks other than those assigned for FUR and polymers. 
Table 2: FTIR values of pure FUR and optimized HME formulations (F6)

\begin{tabular}{|c|c|c|c|c|c|c|c|c|c|}
\hline \multirow[t]{2}{*}{$\begin{array}{l}\text { Chemical } \\
\text { group }\end{array}$} & \multirow{2}{*}{$\begin{array}{l}\text { The standard } \\
\text { range of } \\
\text { absorbance } \\
\text { bands }\left(\mathrm{cm}^{-1}\right)\end{array}$} & \multirow[t]{2}{*}{$\begin{array}{l}\text { Reference } \\
\text { no*. }\end{array}$} & \multirow{2}{*}{$\begin{array}{l}\text { Absorbanc } \\
\text { e band } \\
\text { values of } \\
\text { FUR }\left(\mathrm{cm}^{-1}\right)\end{array}$} & \multicolumn{3}{|c|}{$\begin{array}{l}\text { Observed absorbance band in } \\
\text { a formulation }\left(\mathrm{cm}^{-1}\right)\end{array}$} & \multicolumn{3}{|c|}{$\begin{array}{l}\text { Absorbance band }\left(\mathrm{cm}^{-1}\right) \text { of formulation } \\
\text { F6 (6M stability) }\end{array}$} \\
\hline & & & & F4 & F5 & F6 & $\begin{array}{l}25^{\circ} \mathrm{C} \text { and } \\
60 \% \mathrm{RH}\end{array}$ & $\begin{array}{l}30{ }^{\circ} \mathrm{C} \\
\text { and } 65 \% \mathrm{RH}\end{array}$ & $\begin{array}{l}40{ }^{\circ} \mathrm{C} \text { and } \\
75 \% \mathrm{RH}\end{array}$ \\
\hline $\mathrm{N}-\mathrm{H}$ bending & 1591 & & 1592.91 & - & - & 1610.27 & 1613.16 & 1614.13 & 1610.27 \\
\hline $\begin{array}{l}S=0 \text { stretching } \\
\text { of sulfonamide }\end{array}$ & 1140,1318 & & $\begin{array}{l}1144.55 \\
1324.86\end{array}$ & $\begin{array}{l}1154.19 \\
1333.53\end{array}$ & $\begin{array}{l}1148.4 \\
1332.57\end{array}$ & $\begin{array}{l}1159.97 \\
1333.53\end{array}$ & $\begin{array}{l}1164.79 \\
1338.36\end{array}$ & $\begin{array}{l}\text { 1149.37, } \\
1338.36\end{array}$ & $\begin{array}{l}1155.15 \\
1338.36\end{array}$ \\
\hline $\begin{array}{l}\text { Stretching } \\
\text { vibrations of } \\
\mathrm{SO}_{2} \mathrm{NH}_{2}\end{array}$ & 3260 & 31 & 3285.14 & 3241.75 & 3219.58 & 3231.15 & 3236.93 & 3214.75 & 3237.9 \\
\hline $\begin{array}{l}\text { Non bonded } \\
\text { aromatic } \\
\text { amino group } \\
\text { and a sulfonyl } \\
\text { amide group? }\end{array}$ & $3500-3200$ & & $\begin{array}{l}3285.14, \\
3351.68, \\
3400.85\end{array}$ & 3241.75 & 3219.58 & 3231.15 & 3236.93 & 3214.75 & 3237.9 \\
\hline $\begin{array}{l}\text { Bending } \\
\text { vibration of the } \\
\text { amino group? }\end{array}$ & 1665 & & 1674.87 & 1677.77 & 1671.23 & 1675.84 & 1681.62 & 1681.62 & 1681.62 \\
\hline
\end{tabular}

*Reference no. mentioned belongs to the standard range of absorbance of different chemical, groups of FUR

\section{Tablet evaluation}

Table 3: Tablet evaluation data

\begin{tabular}{|c|c|c|c|c|c|}
\hline Parameters & $\begin{array}{l}\text { Hardness } \\
\left(\mathrm{kp} / \mathrm{cm}^{2}\right)\end{array}$ & $\begin{array}{l}\text { Friability* } \\
(\% w / w)\end{array}$ & $\begin{array}{l}\text { Disintegration } \\
\text { (min) }\end{array}$ & $\begin{array}{l}\% \text { drug release at } 45 \mathrm{~min} \\
\text { in } 0.01 \mathrm{~N} \text { HCL with } 2 \% \text { SLS }\end{array}$ & $\begin{array}{l}\text { \% drug release at } 15 \mathrm{~min} \text { in } \\
\text { pH } 6.8 \text { phosphate buffer }\end{array}$ \\
\hline F4 & $5.95 \pm 1.8$ & 0.54 & 2.3 & $99 \pm 3.5$ & $3.2 \pm 2.5$ \\
\hline F5 & $5.80 \pm 2.2$ & 0.45 & 2.4 & $102 \pm 4.2$ & $2.8 \pm 3.8$ \\
\hline F6 & $6.0 \pm 2.5$ & 0.60 & 2.1 & $103 \pm 3.3$ & $3.8 \pm 4.2$ \\
\hline F6 (S1) & $6.2 \pm 3.5$ & 0.50 & 2.3 & $98 \pm 3.8$ & $4.2 \pm 4.5$ \\
\hline F6 (S2) & $6.0 \pm 4.1$ & 0.48 & 5.8 & $97 \pm 4.0$ & $3.8 \pm 3.5$ \\
\hline F6 (S3) & $5.9 \pm 3.8$ & 0.52 & 6.0 & $99 \pm 3.7$ & $4.0 \pm 3.6$ \\
\hline
\end{tabular}

All values expressed as mean $\pm \mathrm{SD}$, where $\mathrm{n}=3,{ }^{*} \mathrm{n}=20, \mathrm{~S} 1=$ storage condition $25^{\circ} \mathrm{C} \pm 2{ }^{\circ} \mathrm{C}$ and $60 \% \pm 5 \% \mathrm{RH}, \mathrm{S} 2=$ storage condition $30{ }^{\circ} \mathrm{C} \pm 2{ }^{\circ} \mathrm{C}$ and 65 $\% \pm 5 \% \mathrm{RH}, \mathrm{S} 3=$ storage condition $40{ }^{\circ} \mathrm{C} \pm 2{ }^{\circ} \mathrm{C}$ and $75 \% \pm 5 \% \mathrm{RH}$.

All compression parameters were satisfactory and well within the limit. The weight of the tablet was targeted as mentioned in table 1. The tensile strength of all formulations was targeted about 6.0 $\mathrm{kp} / \mathrm{cm}^{2}$ to achieve the desired disintegration time of less than $3 \mathrm{~min}$ and friability of less than $1 \% \mathrm{w} / \mathrm{w}$ as shown in table 3 .

Tablets were disintegrated by erosion mechanism where it didn't swell but disintegrated rapidly. All formulations complied the fineness of dispersion test as well [32].

All three formulations irrespective of the different concentration of plasticizers showed more than $85 \%$ release in $45 \mathrm{~min}$, whereas marketed formulation showed more than $85 \%$ release in $60 \mathrm{~min}$ in $0.01 \mathrm{~N}$ HCL with $2 \%$ SLS. Drug release of test formulations in $\mathrm{pH} 6.8$ buffer was observed less than $10 \%$ release in $15 \mathrm{~min}$, whereas marketed formulation showed about $85 \%$ release. Restricted drug release of test formulations in $\mathrm{pH} 6.8$ buffer assured the masking of bitter taste compared to the marketed formulation.

As $\mathrm{pH}$ of saliva is about 6.75-7.00 [33] drug release in $\mathrm{pH} 6.8$ phosphate buffer utilized to estimate bitter taste inpatient. As a restricted drug release observed in this buffer, no bitter taste will be experienced by patients.

Table 4: Comparative PK parameters of FUR pure API and its HME granules (F6)

\begin{tabular}{lllll}
\hline & $\mathbf{T}_{\max }(\mathbf{h})$ & $\mathbf{C}_{\max }(\boldsymbol{\mu g} / \mathbf{m l})$ & AUC $_{\text {last }}\left(\mathbf{h}^{*} \boldsymbol{\mu g} / \mathbf{m l}\right)$ & AUC \\
\hline Pure FUR & & & & \\
Mean & 0.50 & 8.10 & 16.70 & 22.00 \\
SD & 0.00 & 0.20 & 0.50 & 1.10 \\
CV\% & 0.00 & 2.00 & 3.00 & 5.00 \\
HME Granules & & & & 25.20 \\
Mean & 0.50 & 10.90 & 21.60 & 1.10 \\
SD & 0.00 & 0.20 & 0.70 & 4.00 \\
CV\% & 0.00 & 1.90 & 3.00 & \\
\hline
\end{tabular}

All values expressed as mean $\pm S D$, where $n=6$

\section{Stability study}

When tablets stored in the accelerated and intermediate storage condition DT of tablets increased up to 6 min compared to initial results of less than $3 \mathrm{~min}$. Samples of long term storage condition disintegrated in $2.3 \mathrm{~min}$. Dissolution of all samples was satisfactory. Tablets showed more than $85 \%$ drug release in $0.01 \mathrm{~N}$ HCL with $2 \%$ SLS at $45 \mathrm{~min}$.
XRD study of stability samples shown in fig. 2 revealed the absence of sharp peaks of a crystalline drug and recrystallization even after 6 mo of storage conditions. FTIR data shown in table 2 confirmed no change in chemical groups of FUR during stability study. At accelerated and intermediate stability conditions ( $3 \mathrm{mo}$ and $6 \mathrm{mo}$ ), due to low Tg of eudragit EPO, HME granules might have melted 
partially to make tablets harder and less porous, which lead to increased DT however targeted dissolution in 0.01N HCL with $2 \%$ SLS was achieved in $45 \mathrm{~min}$. Based on stability data it was concluded that the formulation was stable at long term condition, so the product's proposed storage condition would be "Store below $25^{\circ} \mathrm{C} "$ [34].

\section{Animal study}

The retention time of FUR was observed at 4.11 min. A Linear equation used for calculation wasY $=6916.1 \mathrm{X}+6497.8$.

All pharmacokinetic (PK) parameters as the outcome of the animal study presented in table 4 and fig. 3.

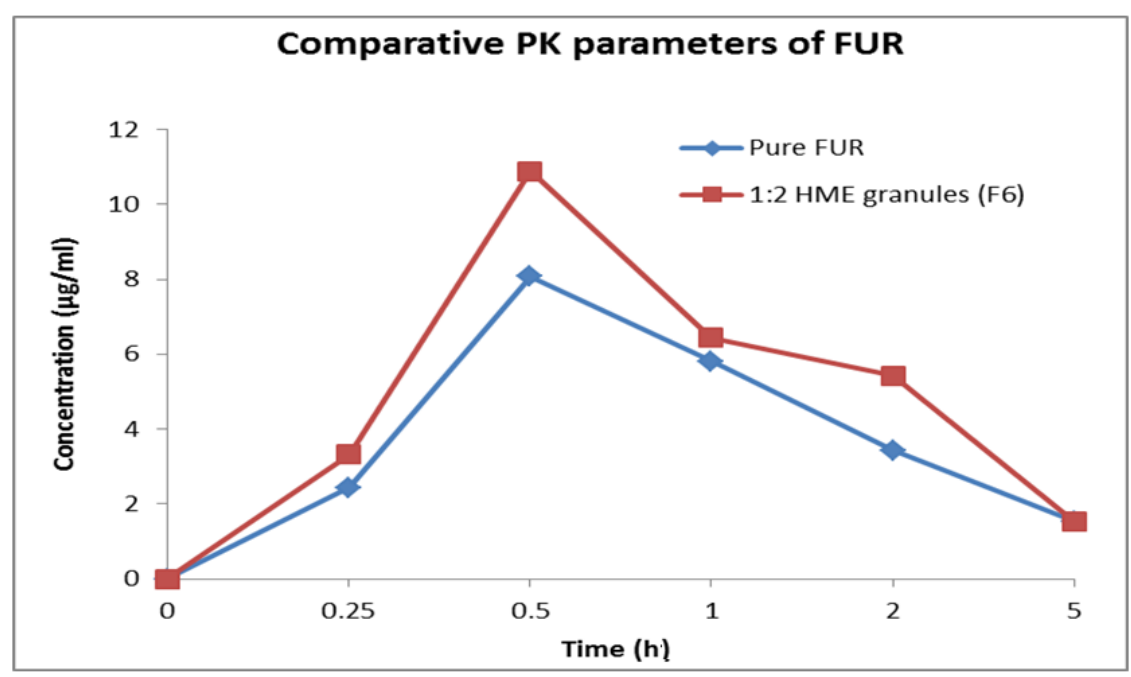

Fig. 3: Comparative PK parameters of FUR pure API and HME granules (F6)

Faster and increased absorption of FUR from HME granules were observed in the animal study. HME granules contained an amorphous form of FUR embedded in the polymer matrix of eudragit EPO and soluplus. Additionally, surfactants used in the HME process. Surfactant like Polysorbate 80 also exhibits Pgp inhibition activity. A cumulative effect of all these factors resulted in increased absorption of FUR at a fast rate. As per literature FUR exhibit about $60-70 \%$ of oral bioavailability [35]. The total absorption of FUR from HME granules was enhanced by about $30 \%$ compared to pure FUR. In humans, FUR is more rapidly absorbed from the upper gastrointestinal (GI) tract following dissolution in the stomach. In case of animal study rapid absorption is observed when administered to the stomach, but slower when administered to the small intestine. The most rapid absorption occurred after administration to the stomach at a pH of 3 [4].

\section{CONCLUSION}

The present study demonstrated the designing and manufacturing of an age-independent pediatric dosage form using HME technology. FUR was hot melt extruded and embedded within a eudragit EPO and soluplus polymer matrix. D: $\mathrm{P}$ 1:2 ratio was adequate to convert the FUR into amorphous form and hold it during storage and stability study. A unique property of eudragit EPO restricts the release of bitter FUR in pH 6.8 phosphate buffer and allows fast and complete release in $0.01 \mathrm{~N}$ HCL with $2 \% \mathrm{w} / \mathrm{w}$ SLS. Proposed packing configuration protected the dosage form from moisture during stability study.

Prepared flexible chewable dispersible tablets can be swallowed intact or administered by dispersing in a sufficient quantity of water or converted into the syrup with the use of a small amount of water (less than $5 \mathrm{ml}$ ). This technology minimizes the challenges of oral dosage form like dose adjustment, accuracy in dose measurement, ease of administration, the requirement of dose administration tools, acceptance of the dosage by pediatric patients. This proposed dosage form achieved all the desired features of pediatric drug delivery.

\section{ACKNOWLEDGMENT}

We would like to be thankful to the Evonik industries for providing the eudragit EPO and BASF technical service center for supplying soluplus. We are also thankful to the technical service center of BASF for allowing the use of their lab and Thermo Fisher scientific for allowing the use of hot melt extruder.

\section{AUTHORS CONTRIBUTIONS}

All the authors have contributed equally

\section{CONFLICT OF INTERESTS}

Declared none

\section{REFERENCES}

1. Ivanovska V, Carin MA, Liset VD, Aukje KM. Pediatric drug formulations: a review of challenges and progress. Pediatrics 2014;134:361-72.

2. Debra LP. Pediatric formulation development: challenges and opportunities from an industry perspective. Worldwide pharmaceutical sciences. US FDA. Presentation to the pediatric oncology subcommittee of the oncologic drugs advisory committee; 2009.

3. Formulations of choice for the pediatric population. Reflection paper by European Medicines Agency. Pre-authorization Evaluation of Medicines for Human Use. Committee for Medicinal Products for Human Use (CHMP); 2006.

4. Ghulam M, Shujaat AK, Muhammad NH, Izhar H. Comparative evaluation of various solubility enhancement strategies for furosemide. Pak J Pharm Sci 2014;27:963-73.

5. Granero GE, Longhi MR, Mora MJ, Junginger HE, Midha KK, Shah VP. Biowaiver monographs for immediate release solid oral dosage forms: furosemide. J Pharm Sci 2010;6:2544-56.

6. Product information leaflet. Lasix (Furosemide) tablets 20, 40 and $80 \mathrm{mg}$. By Sanofi Aventis. Available from: https://www.accessdata.fda.gov/drugsatfda_docs/label/2012/ 016273s066lbl.pdf. [Last accessed on 05 Mar 2019].

7. Rafik K. Prodrugs for masking the bitter taste of drugs. In: Li DS. editor. Application of nanotechnology in drug delivery. $1^{\text {st }}$ ed; 2014. p. 399-445.

8. Zainab EJ. Formulation and evaluation of furosemide liquisolid compact. Int J Appl Pharm 2017;9:39-48.

9. Mohammed M, Ali N. Continuous manufacturing via hot-melt extrusion and scale up: regulatory matters. Drug Discovery Today 2017;22:340-51. 
10. Suniket F, Sarah R. Taste-masking, pharmaceutical tastemasking technologies. Drug Dev Delivery 2015;15:64-8.

11. Hemlata P, Roshan VT, Michael AR. Hot-melt extrusion: from theory to application in pharmaceutical formulation. AAPS PharmSciTech 2016;17:20-42.

12. Jia L, Feng C, Can Z, Qineng P. Use of polymer combinations in the preparation of solid dispersions of a thermally unstable drug by hot-melt extrusion. Acta Pharm Sin B 2013;4:263-72.

13. Kolter K, Karl M, Gryczke A. Hot melt extrusion with BASF pharma polymers. Extrusion Compendium. $2^{\text {nd }}$ ed; 2012.

14. Kamlesh M, Rahul J, Mandar M, Subhashis C. Exploring Eudragit EPO for taste masking of bitter drugs using hot melt extrusion. AAPS Annual Meeting and Exposition. Poster No. W4205; 2011.

15. Chang RK, Peng Y, Trivedi N, Shukla AJ. Polymethacrylates. In: Raymond CR, Paul JS, Marian EQ. editors. Handbook of Pharmaceutical Excipients. $6^{\text {th }}$ ed. London: Pharmaceutical Press; 2009. p. 525-33.

16. Keating AV, Soto J, Tuleu C, Forbes C, Zhao M, Craig D. Solid state characterization and taste masking efficiency evaluation of polymer-based extrudates of isoniazid for pediatric administration. Int J Pharm 2018;536:536-46.

17. Maniruzzaman M, Boateng JS, Chowdhry BZ, Snowden MJ, Douroumis D. A review on taste masking of bitter APIs: hot melt extrusion (HME) evaluation. Drug Dev Ind Pharm 2014;2:145-56.

18. Ghebremeskel AN, Vemavarapu C, Lodaya M. Use of surfactants as plasticizers in preparing solid dispersions of poorly soluble API: the selection of polymer-surfactant combinations using solubility parameters and testing the processability. Int J Pharm 2007;328:119-29.

19. Sandeep K, Mohanvarma M, Veerabhadhraswamy P. Oral lipidbased drug delivery systems-an overview. Acta Pharm Sin B 2013;6:361-72.

20. Deshmukh V, Mulik S, Deshmukh T, Kasat K. Solubility enhancement of efavirenz hydrochloride by hot melt technique. Cur Pharma Res 2011;4:320-36.

21. Edgar R, Ketaki P, Firouz A. Prediction of API solubility in solid solutions using modified solubility parameters, film casting and melt extrusion. AAPS Annual Meeting Exposition, Poster No. W4313; 2011.
22. Tablet Friability. Chapter 1216. United State Pharmacopoeia 39 (USP 39)/National Formulary 34 (NF 34); 2016. p. 1609.

23. Fell JT, Newton JM. Determination of tablet strength by diametral compression test. J Pharm Sci 1970;59:688-91.

24. Disintegration. Chapter 701. United State Pharmacopoeia 39 (USP 39)/National Formulary 34 (NF 34); 2016. p. 537.

25. Dissolution. Chapter 711. In: United State Pharmacopoeia 39 (USP 39)/National Formulary 34 (NF 34); 2016. p. 540.

26. Stability testing of new drug substances and products. ICH harmonized tripartite guideline. International Conference on Harmonization (ICH) of technical requirements for registration of pharmaceuticals for human use; 2003:Q1A(R2). p. 1-18.

27. Furosemide tablets monograph. United States Pharmacopoeia 39 (USP 39)/National Formulary 34 (NF 34); 2009. p. 4061.

28. Dejan D, Soluplus. In: Thomas R. editor. Solubility enhancement with BASF pharma polymer. Solubilizer Compendium; 2011. p. 67-8.

29. Dan W. Excipients for formulation success, cover story. Pharm Technol 2016;40:22-7.

30. Farha AS, Shubhrajit M. Formulation and evaluation of tenofovir disoproxil fumarate immediate-release tablets. Int J Inno Pharm Sci Res 2013;2:252-65.

31. Shin Oh I, Lee Y, Choi H, Choi J. Enhanced dissolution of furosemide by co-precipitating or co-grinding with crospovidone. Int J Pharm 1998;175:17-24.

32. Tablets general monograph. In: British Pharmacopoeia. Volume III; 2017. p.73-6.

33. Elaine NM. The digestive system. In: Human anatomy and physiology. $6^{\text {th }}$ ed; 2006. p. 881.

34. Guideline on a declaration of storage conditions: A: In the product information of medicinal products, B: for active substances. European Medicines Agency. Committee for medicinal products for human use (CHMP); 2003. Available from:

http://www.ema.europa.eu/docs/en_GB/document_library/Sc ientific_guideline/2009/09/WC500003468.pdf. [Last accessed on 10 Jan 2017].

35. Sandeep K, Arun N. Formulation, optimization and in vitro evaluation of gastroretentive mucoadhesive microspheres of furosemide. Int J Appl Pharm 2016;7:392-8. 